\title{
UTILIZAÇÃO DE MICRO-ORGANISMOS ISOLADOS DE KEFIR COMO CULTURA PADRÃO PARA DETECÇÃO DE INIBIDORES NO LEITE
}

Talita Schneid Tejada ${ }^{1}$

Marina Ferrasso ${ }^{1}$

Carolina Janelli da Silva ${ }^{1}$

Priscila Alves Dias ${ }^{1}$

Helenice de Lima Gonzalez ${ }^{1}$

Cláudio Dias Timm ${ }^{1}$

TEJADA, T. S.; FERRASSO, M.; SILVA, C. J. da; DIAS, P. A.; GONZALEZ, H. de L.; TIMM, C. D. Utilização de micro-organismos isolados de kefir como cultura padrão para detecção de inibidores no leite. Arq. Ciênc. Vet. Zool. UNIPAR, Umuarama, v. 18, n. 4, p. 225-229, out./dez. 2015.

RESUMO: Resíduos de inibidores em leite são um problema para saúde pública e sua detecção é muito importante. Bactérias lácticas podem ser utilizadas como cultura teste no método de Disco de Filtro substituindo o Geobacillus stearothermophilus. O objetivo deste trabalho foi analisar o potencial de bactérias lácticas isoladas de grãos de kefir para utilização como cultura padrão no Teste do Disco do Filtro para detecção de inibidores no leite. Foram testadas 20 bactérias láticas quanto à sensibilidade a 16 diferentes antibióticos por meio da técnica de difusão de disco. A bactéria com sensibilidade ao maior número de antimicrobianos foi testada frente a diferentes concentrações dos antibióticos, e determinado seu limite de detecção, o qual foi comparado com a cepa padrão da técnica. A cepa teste LIPOA 5079 foi a única que apresentou sensibilidade igual ou maior que a cepa padrão na técnica de difusão de disco e foi utilizada como cultura teste na técnica de detecção de inibidores. A cepa teste pode ser utilizada como cultura padrão para Teste do Disco do Filtro para detecção de resíduos dos antimicrobianos ampicilina, azitromicina, cefalexina, ciprofloxacino, doxicilina, enrofloxacina, eritromicina, gentamicina e neomicina no leite. PALAVRAS-CHAVE: Antibacterianos. Lactobacillus. Produtos lácteos. Saúde pública.

\section{USE OF MICRO-ORGANISMS ISOLATED FROM KEFIR CULTURE AS STANDARD FOR THE DETECTION OF INHIBITORS IN MILK}

\begin{abstract}
Antibiotic residues in milk is a public health problem and its detection is very important. Lactic acid bacteria can be used as a test culture in the disk diffusion method instead of Geobacillus stearothermophilus. The aim of this study was to analyze the potential of lactic acid bacteria isolated from kefir grains to use as a standard culture in the disk diffusion method for inhibitors detection in milk. The sensitivity of twenty lactic acid bacteria was tested to 16 different antibiotics by disk diffusion technique. The bacteria that showed sensitivity to the largest number of antibiotics was tested with different concentrations of it, and determined its detection limit, which was compared with the standard strain of the technique. The test strain LIPOA 5079 was the only one that showed the same or greater sensitivity compared to the standard strain in the disk diffusion assay and it was used as the test culture for the inhibitors detection technique. The strain test can be used as a standard culture for the disk diffusion test for detecting residues of antibiotics like ampicillin, azithromycin, cephalexin, ciprofloxacin, doxycycline, enrofloxacin, erythromycin, gentamicin and neomycin in milk.
\end{abstract}

KEYWORDS: Anti-bacterial agents. Dairy products. Lactobacillus. Public health.

\section{UTILIZACIÓN DE MICROORGANISMOS AISLADOS DE KÉFIR COMO CULTURA ESTÁNDAR PARA DETECCIÓN DE INHIBIDORES EN LA LECHE}

RESUMEN: Residuos de inhibidores en la leche es un problema para la salud pública y su detección es muy importante. Bacterias lácticas pueden ser utilizadas como cultivo prueba en el método de Disco de Filtro, sustituyendo el Geobacillus stearothermophilus. El objetivo de este estudio ha sido analizar el potencial de bacterias lácticas aisladas de granos de kéfir, como cultura estándar en la Prueba de Disco, para detección de inhibidores en la leche. Se han testado 20 bacterias lácticas, cuanto a la sensibilidad a 16 antibióticos diferentes, a través de la técnica de difusión de disco. La bacteria con sensibilidad al mayor número de antimicrobianos ha sido probada ante a diferentes concentraciones de antibióticos, y determinado su límite de detección, que se comparó con la cepa estándar de la técnica. La cepa de ensayo LIPOA 5079 fue la única que presentó sensibilidad igual o mayor que la cepa estándar en el método de difusión en disco y se ha utilizado como cultivo prueba en la técnica de detección de inhibidores. La cepa prueba puede ser utilizada como cultura estándar en Prueba del Disco de Filtro para detección de residuos de los antimicrobianos ampicilina, azitromicina, cefalexina, ciprofloxacina, doxicilina, enrofloxacina, eritromicina, gentamicina y neomicina en la leche.

PALABRAS CLAVE: Antibacterianos. Lactobacillus. Productos lácteos. Salud pública.

DOI: https://doi.org/10.25110/arqvet.v18i4.2015.5748

${ }^{1}$ Universidade Federal de Pelotas, Campus Capão do Leão, Prédio 34, Laboratório de Inspeção de Produtos de Origem Animal, Faculdade de Veterinária, Rio Grande do Sul, Brasil. talitastejada@gmail.com 


\section{Introdução}

As infecções da glândula mamária são comuns em grande parte das granjas leiteiras, sua etiologia é complexa e variada, assim como seu controle, e influenciam diretamente a composição do leite (NIELSEN; EMANUELSON, 2013). Não só a mastite, mas todo processo patológico de origem infecciosa, como cistite, actinobacilose, enterites, é normalmente combatido com antibioticoterapia, principalmente as infecções pós-parto, como distocias e endometrites (GHANEM et al., 2013). O uso de antibióticos, seja com fins terapêuticos ou como suplemento dietético incorporado à alimentação animal, pode levar ao aparecimento de resíduos desses medicamentos no leite, visto que essas drogas são veiculadas via corrente circulatória até o leite quando este está sendo sintetizado. A presença de inibidores de micro-organismos no leite acarreta sérios problemas tecnológicos e de saúde pública (BRITO; LANGE, 2005; SILVA; SARMENTO; FRANCA, 2008; SOUZA, 2006).

Vários métodos qualitativos e quantitativos podem ser utilizados para a detecção de inibidores (ŽVIRDAUSKIENĖ; ŠALOMSKIENĖ, 2007). Segundo Tronco (2008), o método do Disco de Filtro é um teste qualitativo sensível e específico, que pode apresentar teste negativo ou positivo em função de uma concentração limite predeterminada para uma droga de triagem, indicando se esta está presente ou não em concentrações acima de um limite de segurança. A bactéria utilizada no teste é o Geobacillus stearothermophilus, o qual tem temperatura ideal de crescimento $55^{\circ} \mathrm{C}$. Esta temperatura é um fator limitante da técnica, pois a maioria dos laboratórios trabalha com micro-organismos que crescem à temperatura de aproximadamente $37^{\circ} \mathrm{C}$, sendo necessário manter um equipamento a $55^{\circ} \mathrm{C}$ exclusivamente para estas análises.

Kefir é um leite fermentado, ácido, levemente alcoólico, produzido artesanalmente a partir de grãos que contêm uma população relativamente estável de micro-organismos simbióticos, imersos em uma matriz composta de polissacarídeos e proteínas (ABRAHAM; DE ANTONI, 1999; YOVANOUDI et al., 2013). Os micro-organismos isolados dos grãos de kefir são característicos e estáveis, na sua grande maioria pertencem aos gêneros Lactobacillus, Lactococcus, Leuconostoc e Saccharomyces (VARDJAN et al., 3013; NALBANTOGLU et al., 2014).

A identificação de micro-organismos sensíveis aos antibióticos mais comumente utilizados em medicina veterinária, os quais possam ser utilizados nas análises de resíduos de inibidores em leite, é importante para a abrangência dos testes, de forma a detectar um número elevado de antimicrobianos. Sendo assim, este trabalho teve como objetivo analisar o potencial de bactérias lácticas isoladas de grãos de kefir para utilização como cultura padrão no Teste do Disco do Filtro para detecção de inibidores no leite.

\section{Materiais e Métodos}

Foram utilizadas 20 bactérias láticas aeróbicas isoladas de grãos de kefir em estudo prévio (DIAS, 2011). As cepas foram recuperadas em caldo De Man, Rogosa e Sharpe
$(\mathrm{MRS})^{1}$ a $37^{\circ} \mathrm{C}$ por $48 \mathrm{~h}$ e testadas quanto à sensibilidade a antibióticos por meio da técnica de difusão de disco, segundo CLSI (2005). Foram utilizados os seguintes antibióticos com as respectivas concentrações nos discos: amoxicilina $10 \mathrm{mcg}$, ampicilina $10 \mathrm{mcg}$, bacitracina $10 \mathrm{UI}$, cefalexina 30 $\mathrm{mcg}$, cloranfenicol $30 \mathrm{mcg}$, enrofloxacina $5 \mathrm{mcg}$, eritromicina $15 \mathrm{mcg}$, estreptomicina $10 \mathrm{mcg}$, gentamicina $10 \mathrm{mcg}$, neomicina $30 \mathrm{mcg}$, norfloxacina $10 \mathrm{mcg}$, penicilina G $10 \mathrm{UI}$, polimixina B $300 \mathrm{mcg}$, sulfonamidas $300 \mathrm{mcg}$, tetraciclina $30 \mathrm{mcg}$, trimetoprima $5 \mathrm{mcg}^{2}$.

Após a seleção das bactérias com sensibilidade ao maior número de antimicrobianos foram realizados testes utilizando leite com diferentes concentrações dos antibióticos. Foram adicionadas concentrações decrescentes $\left(10^{0}, 10^{-1}\right.$ e $10^{-2}$ ) de antibióticos comerciais (amoxacilina, ampicilina, azitromicina, cefalexina, ciprofloxacina, doxicilina, enrofloxacina, eritromicina, gentamicina, levofloxacina, neomicina, tetraciclina) em leite sabidamente sem antibiótico para determinação do limite de detecção do teste. As concentrações iniciais $\left(10^{\circ}\right)$ foram determinadas com base nos limites máximos de resíduos de antimicrobianos do Programa de Análise de Resíduos de Medicamentos Veterinários em Alimentos de Origem Animal - PAMVET (BRASIL, 2003) estabelecidos para cada antibiótico testado. Discos de papel filtro estéril foram imersos no leite com antibiótico, conforme descrito anteriormente, colocados em uma placa com ágar Müller-Hinton previamente semeada com a cepa teste e incubadas à $37^{\circ} \mathrm{C}$ por 48 horas. Após a incubação, os halos de inibição ao redor dos discos foram medidos, conforme a técnica padrão (CLSI, 2005). O mesmo foi feito nas diferentes concentrações de antibióticos testadas $\left(10^{0}, 10^{-1}\right.$ e $\left.10^{-2}\right)$. Os mesmos testes, nas mesmas concentrações, foram feitos utilizando a cepa padrão G. stearothermophilus (ATCC 12980). O experimento foi realizado em triplicata e os resultados foram avaliados pela média dos halos em cada concentração.

\section{Resultados e Discussão}

A cepa teste LIPOA 5079 foi a única dentre as 20 bactérias lácticas isoladas de grãos de kefir testadas que apresentou sensibilidade a todos antimicrobianos utilizados na técnica de difusão de disco testados neste estudo (Tabela 1). Esta cepa apresentou sensibilidade a todos antibióticos, assim como a cepa padrão, sendo utilizada como cultura teste na técnica do leite com resíduo de antimicrobiano.

\footnotetext{
${ }^{1}$ Acumedia, Lansing, Michigan.

Sensidisc DME, DME, São Paulo.
} 
Tabela 1: Halos de inibição (em mm) das bactérias lácticas isoladas de grãos de kefir na técnica de difusão de disco quanto aos antibióticos testados.

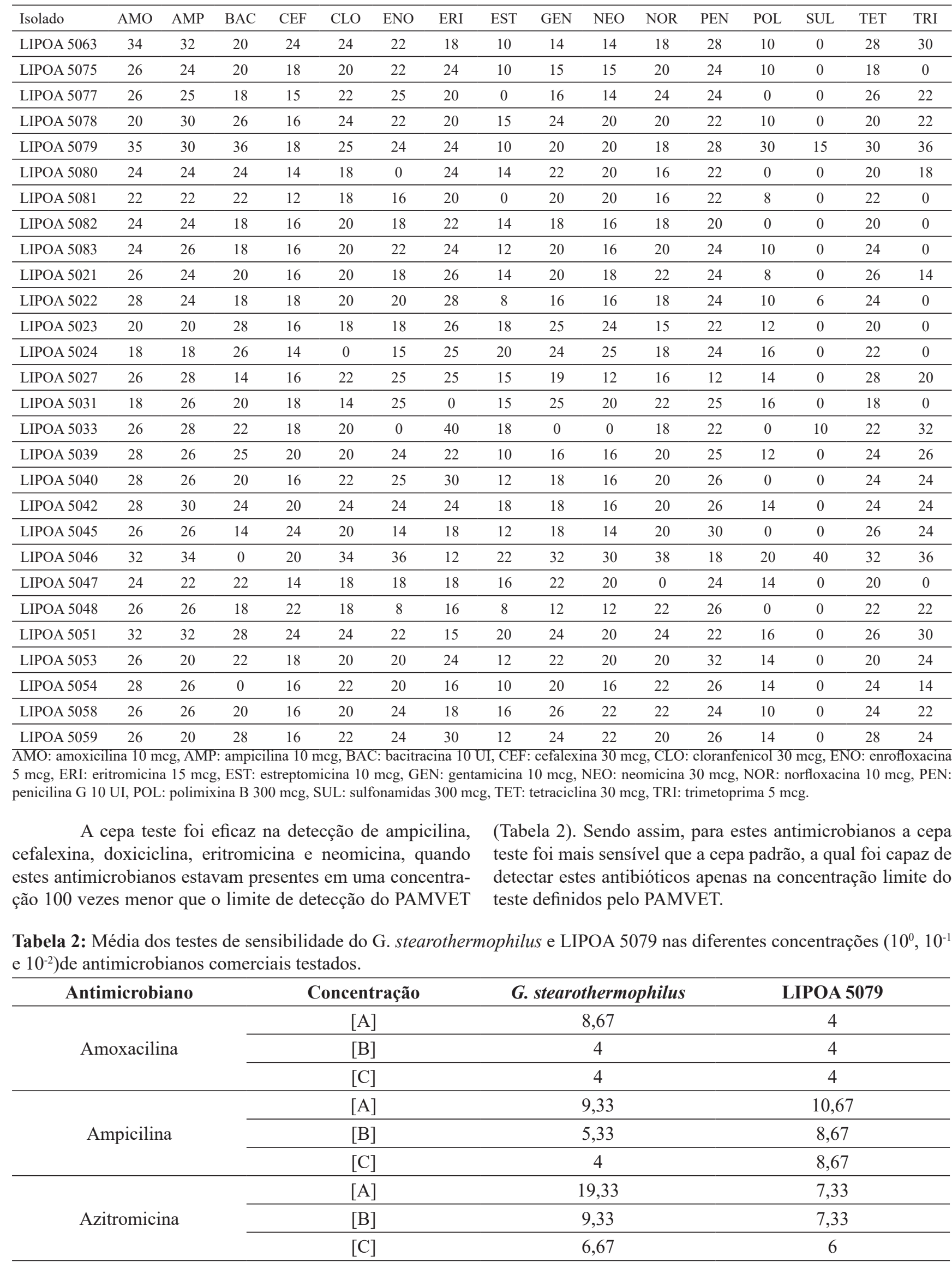




\begin{tabular}{|c|c|c|c|}
\hline \multirow{3}{*}{ Cefalexina } & {$[\mathrm{A}]$} & 8,67 & 10 \\
\hline & [B] & 7,33 & 8,67 \\
\hline & {$[\mathrm{C}]$} & 6 & 8,67 \\
\hline \multirow{3}{*}{ Ciprofloxacina } & {$[\mathrm{A}]$} & 9,33 & 6,67 \\
\hline & {$[\mathrm{B}]$} & 7,33 & 5,33 \\
\hline & {$[\mathrm{C}]$} & 6,67 & 4,67 \\
\hline \multirow{3}{*}{ Doxiciclina } & {$[\mathrm{A}]$} & 9,33 & 10 \\
\hline & [B] & 8 & 8,67 \\
\hline & {$[\mathrm{C}]$} & 8 & 6 \\
\hline \multirow{3}{*}{ Enrofloxacina } & {$[\mathrm{A}]$} & 8,67 & 8,67 \\
\hline & [B] & 6,67 & 6,67 \\
\hline & {$[\mathrm{C}]$} & 6 & 6 \\
\hline \multirow{3}{*}{ Eritromicina } & {$[\mathrm{A}]$} & 7,33 & 12 \\
\hline & [B] & 4 & 8,67 \\
\hline & {$[\mathrm{C}]$} & 4 & 8,67 \\
\hline \multirow{3}{*}{ Gentamicina } & {$[\mathrm{A}]$} & 8 & 8 \\
\hline & [B] & 6,67 & 6,67 \\
\hline & {$[\mathrm{C}]$} & 5,33 & 5,33 \\
\hline \multirow{3}{*}{ Levofloxacina } & {$[\mathrm{A}]$} & 8 & 4 \\
\hline & [B] & 6,67 & 4 \\
\hline & {$[\mathrm{C}]$} & 6 & 4 \\
\hline \multirow{3}{*}{ Neomicina } & [A] & 11,33 & 12 \\
\hline & [B] & 6 & 7,33 \\
\hline & {$[\mathrm{C}]$} & 4 & 6,67 \\
\hline \multirow{3}{*}{ Tetraciclina } & {$[\mathrm{A}]$} & 6 & 4 \\
\hline & [B] & 4 & 4 \\
\hline & {$[\mathrm{C}]$} & 4 & 4 \\
\hline
\end{tabular}

$[\mathrm{A}]=$ limite padrão do PAMVET $\left(10^{\circ}\right),[\mathrm{B}]=10 \mathrm{x}$ menos o limite padrão do PAMVET $\left(10^{-1}\right),[\mathrm{C}]=100 \mathrm{x}$ menos o limite padrão do PA$\operatorname{MVET}\left(10^{-2}\right)$.

Ambas as cepas foram capazes de detectar os antimicrobianos enrofloxacina, gentamicina, azitromicina e ciprofloxacina quando estes estavam presentes em uma concentração 100 vezes menor que o limite de detecção do PAMVET. No caso de azitromicina e ciprofloxacina, os halos da cepa padrão foram maiores que o da cepa teste, indicando maior sensibilidade da cepa teste a estes antimicrobianos.

Somente no caso dos antimicrobianos amoxacilina, levofloxacina e tetraciclina a cepa teste não foi tão eficiente como a cepa padrão, pois não detectou estes antimicrobianos nem na concentração limite descritos pela PAMVET.

Segundo Tronco (2008), para a validação de um teste é importante sua sensibilidade e especificidade, a interferência de outras drogas, variação de tempo e execução da prova, volume da amostra e temperatura. No caso desta pesquisa, observou-se que o teste de disco utilizando a cepa LIPOA 5079 foi capaz de detectar a presença de resíduos da maioria dos antibióticos testados. Além disso, a substituição da cepa padrão pela cepa teste facilita a execução da técnica, pois as amostras podem ser incubadas em estufas utilizadas na rotina laboratorial, tendo em vista que a temperatura ideal de crescimento dos lactobacilos é $37^{\circ} \mathrm{C}$.

\section{Conclusão}

A bactéria ácido-láctica cepa LIPOA 5079 isolada de grãos de kefir pode ser utilizada como cultura padrão para Teste do Disco do Filtro para deteção de resíduos dos antimicrobianos ampicilina, azitromicina, cefalexina, ciprofloxacina, doxicilina, enrofloxacina, eritromicina, gentamicina e neomicina no leite. $O$ custo do teste se torna mais acessível e o tempo na aquisição do resultado mais curto.

\section{Referências}

ABRAHAM, A. G.; DE ANTONI, G. L. Characterization of kefir grains grow in cow's milk and soya milk. Journal of Dairy Research, v. 66, p. 327-333, 1999.

BRASIL. Agência Nacional de Vigilância Sanitária. Programa Nacional de Análise de Resíduos de Medicamentos Veterinários em Alimentos Expostos ao Consumo - PAMVet - Resolução RDC no 253, de 16 de setembro de 2003. Diário Oficial [da] República Federativa do Brasil, Brasília, 18 set. 2003.

BRITO, M. A. V. P.; LANGE, C. C. Resíduos de antibióticos no leite. Juiz de Fora: Embrapa, 2005. 4 p. 
(Comunicado técnico Embrapa Gado de Leite).

CLSI. Padronização dos testes de sensibilidade a antimicrobianos por disco-difusão: Norma Aprovada Oitava Edição. M2-A8, v. 23, n. 1, 2005. Disponível em: $<$ http://www.anvisa.gov.br/servicosaude/manuais/clsi/ clsi_OPASM2-A8.pdf>. Acesso em: 02 fev. 2015.

DIAS, P. Atividade antimicrobiana de microrganismos presentes em grãos de kefir. 2011. 44 f. Dissertação (Mestrado em Ciências Veterinárias) - Departamento de Veterinária Preventiva, Faculdade de Medicina Veterinária, Universidade Federal de Pelotas, Pelotas, 2011.

GHANEM, M. E. et al. Mycoplasma infection in the uterus of early postpartum dairy cows and its relation to dystocia and endometritis. Theriogenology, v. 79, n. 1, p. 180-185, 2013 .

NALBANTOGLUU, C. A. et al. Metagenomic analysis of the microbial community in kefir grains. Food

Microbiology, v. 41, p. 42-51, 2014.

NIELSEN, C.; EMANUELSON, U. Mastitis control in Swedish dairy herds. Journal of Dairy Science, v. 96, n. 11, p. 6883-6893, 2013.

SILVA, M. V. M.; SARMENTO, A. M. C.; FRANCA, A. P. Resíduos de antibiótico no leite e seus efeitos na saúde pública: uma preocupação constante. In: CONGRESSO BRASILEIRO DE MEDICINA VETERINÁRIA, 35., 2008, Gramado. Proceedings... Gramado: SOVERGS, 2008.

SOUZA, R. C. Resíduos de antibiótico no leite. Rio de Janeiro, 2006. 44 f. Monografia (Pós-graduação "Lato sensu" em higiene e inspeção de produtos de origem animal/vigilância sanitária de alimentos) - Universidade Castelo Branco, São Paulo, 2006.

TRONCO, V. M. Manual para inspeção da qualidade do leite. 3. ed. Santa Maria: UFSM, 2008. 206 p.

VARDJAN, T. et al. Characterization and stability of lactobacilli and yeast microbiota in kefir grains. Journal of Dairy Science, v. 96, n. 5, p. 2729-2736, 2013.

YOVANOUDI, M. et al. Flow behavior studies of kefir type systems. Journal of Food Engineering, v. 118, n. 1, p. 4148, 2013.

ŽVIRDAUSKIENĖ, R.; ŠALOMSKIENĖ, J. An evaluation of different microbial and rapid tests for determining inhibitors in milk. Food Control, v. 18, n. 5, p. 541-547, 2007. 